\title{
Individualism: valued differently by parents and teachers of primary, junior high and high school students
}

\author{
Florence Loose
}

Received: 20 February 2007 / Accepted: 29 October 2007 / Published online: 9 January 2008

(C) Springer Science+Business Media B.V. 2007

\begin{abstract}
The present study was designed to examine if individualism, a core characteristic of Western societies, is socially valued in two fundamental institutions: Family and school. Parents and teachers of fourth graders (primary school), sixth graders (junior high school) and tenth graders (high school) completed an Individualism Scale (covering the main factors of self-realization, autonomy, emotional independence and social differentiation) which was adapted for each grade. For each item, they had to choose the answer their child, or students, would need to give in order to make a good, or bad, impression. The results showed that individualism is valued differently as a function of the evaluator. Parents valued it in their children (with the exception of sixth graders) although teachers actually devalued it in their students. Additionally, individualism appeared as a multifaceted phenomenon since its different components were not judged consistently.
\end{abstract}

Keywords Individualism · Valuation · Parents · Teachers

It is a common claim that individualism represents the central feature of Western civilization (e.g., Mendras 1997; Riesman et al. 1961; Sampson 1977, 1988). Indeed, people in our society like the idea that they are different from others. They aspire to autonomy and independence in their daily life and usually their own interests prevail over collective interests. So individualism really seems to embody a commonplace, and resolute, way of behaving.

According to some authors, if people are strongly individualistic in Western societies, it is principally for the reason that primary socialization agents-i.e., parents and teachers-encourage children, very early, to behave in an individualistic manner

F. Loose $(\varangle)$

Laboratoire de Psychologie Sociale et Cognitive, UMR, CNRS 6024, Université Blaise Pascal, 34 Avenue Carnot, 63037 Clermont-Ferrand, France

e-mail: loose@iut.u-clermont1.fr 
(e.g., Ranjard 1997). This would mean that these agents, whose characteristic role is one of social evaluation, value this kind of behaviour in their children and students. However, this proposition has not been tested thoroughly in 'individualistic' countries apart from the US.

The present study focuses on a relatively neglected area within individualism research by exploring whether individualism is judged desirable by agents in two key institutions - the family and the school.

In the following sections, an attempt is made to refine the meaning of individualism by listing its core components, then an examination is given of how authors usually perceive the valuation of this phenomenon in families and at school. Their judgments, however, are mainly based on personal opinion, revealing a necessity to explore this question deeper, at a more empirical level.

A study, therefore, is introduced that is designed to empirically investigate the value assigned to individualism by parents and teachers in France.

\section{The essential dimensions of individualism}

In a very general sense, the notion of individualism is about the relationship between the individual and the community to which he/she belongs. Numerous definitions stressing specific concepts of individualism have been proposed in the psychological literature (e.g., Hofstede 1980; Hui and Triandis 1986; Sampson 1977; Triandis 1995; Waterman 1981). Despite this conceptual plurality, some common core components of individualism can be extracted. So in order to investigate this phenomenon more precisely, it seems more appropriate to refer to its primary components rather than to choose one definition in particular. Four main components can be highlighted:

1. Self-realization: Individualists decide and act more on the basis of whether an action leads to personal gain rather than collective gain. For them, personal goals and success prevail over collective ones (e.g., Bellah et al. 1985; Dubois and Beauvois 2005; Gelfand et al. 1996; Yamaguchi 1994).

2. Autonomy: Individualists try to have the greatest freedom of action and thought. They choose their own goals and make their own decisions, deciding that they don't have to be influenced by other people (e.g., Fowers et al. 1995; Hui and Triandis 1986; Realo et al. 2002; Triandis 1995; Triandis et al. 1990; Waterman 1981).

3. Emotional independence: Individualists feel that others are not involved in their life, and that they are not involved in others' lives, except if they are particularly close to them (e.g., Hofstede 1980; Hui and Triandis 1986; Triandis et al. 1990; Yang 1988).

4. Social differentiation: Individualists want to avoid conformity, and focus more on distinguishing themselves from others than on their resemblance with them. So they prefer to see themselves as unique and different from other people rather than similar to them (e.g., Codol 1984; Markus and Kitayama 1991; Realo et al. 2002; Vignoles et al. 2000).

Since there is strong agreement about these four components, it is safe to assume they form the main characteristics of an individualistic person. Without questioning 
the validity of other models, the components proposed here permit an examination of individualism in a more empirical way.

\section{Individualism in family and at school}

As noted earlier, numerous researchers tend to think that parents and teachers, as 'socialization agents', encourage and value the expression of individualism in children and students.

With regards to individualism in a family context, studies are predominantly crosscultural, comparing value priorities in American families to families from collectivist countries (e.g. Latino or Asian ones). These are conducted via interviews or questionnaires about childrearing practices (e.g., Harwood et al. 1995, 1996). These studies generally find a greater tendency for Euro-Americans to value individualistic characteristics such as autonomy, uniqueness, and individual achievement (Damon 1995; Harkness et al. 1992; Harwood 1992; Leyendecker et al. 2002; Stewart et al. 1999), whereas Latino or Asian parents are more likely to encourage children to view themselves as part of a group and not emphasize their differences from others (Markus and Kitayama 1991). But ultimately very little is known about other individualistic countries apart from the US.

In accordance with the results from American families, we expect that French parents, (i.e. from another individualistic population), although widely understudied, would value individualism in their children. The present study also considered if this would remain consistent irrespective of the children's educational level, an additional facet largely unanswered in previous research. Loose (2001), who examined the evolution of individualism with school grade, has shown that it is not a linear evolution, since sixth graders (entering into junior high school) are surprisingly less individualistic than younger children from primary school and than older students from junior high and high school. Given that family is usually considered as a central context for the development of children's values (e.g., Gecas 1976), we can wonder if this decrease of individualism in sixth graders could come from the fact that parents do not always value individualism in their children in the same way, whatever their academic position. It is the reason why this study also aimed to examine if parents' judgment about individualism is connected or not to their children's educational level.

Regarding individualism in a school context, little research has been conducted. In general, however, researchers speculate that this particular institution highlights individualism because Western schools (and particularly US schools) encourage children to become independent thinkers who principally must care about self-achievement and fulfilling their own needs (Trumbull et al. 2000). This would be reflected in the organizational patterns of learning in the classroom. Teachers in individualistic societies would focus, above all, on the individual and emphasize individual responsibility for learning (Estrin and Nelson-Barber 1995). Researchers suggest, therefore, that teachers would also encourage individualism in their students in Western societies. Similarly, Ranjard (1997) submits that French teachers are producers of individualists. But such ideological considerations do not profess to know with any degree of certainty if teachers actually judge individualism as a desirable characteristic for their 
students. In addition, as for parents, it is not known if there is a difference in the valuation of individualism as a function of the students' school level (i.e. a difference between primary, junior high and high school). Consequently, the question arises as to whether parents and teachers judge children's individualism consistently, regardless of the child's educational level.

Finally, it is noticeable that individualism is usually examined as a whole, and not as a function of its different components. It would be of interest, therefore, to explore also the valuation of each of the main components of individualism. Determining if they are all judged in the same manner or not should lead to a more complete understanding of the value of individualism as a multifaceted phenomenon (e.g., Dubois and Beauvois 2005; Loose 2000).

The study reported here was designed in order to examine the value assigned to individualism - through its four major components (self-realization, autonomy, emotional independence, and social differentiation) — by parents and teachers. All participants came from French populations referred to elsewhere as being indicative of the most individualist regions (e.g., Hofstede 1980; Ranjard 1997; Schwartz 1994).

\section{Method}

\subsection{Participants}

A sample of 183 parents and 152 teachers was selected for this study. Participants were 62 parents and 50 teachers of fourth graders (i.e., primary school), 60 parents and 50 teachers of sixth graders (i.e. junior high school), 61 parents and 52 teachers of tenth graders (i.e. high school).

Parents and teachers were recruited from a variety of French establishments. They received an Individualism Scale, and a cover letter with instructions on how to complete the scale, and an outline of the procedures that would be used to assure participant anonymity. This material was distributed to children who presented it to their parents and returned it, completed, to school, and to the school directors who presented it to teachers and, likewise, ensured its return once completed.

\subsection{Material}

The study was preceded by a pilot study focussed on the construction and validation of the Individualism Scale, made up of statements covering each of the four components discussed before (i.e., self-realization, autonomy, emotional independence, and social differentiation).

The existing scales measuring individualism (e.g., the COS-Bierbrauer et al. 1994; the COLINDEX — Chan 1994; Dubois and Beauvois 1999; the INDCOL-Hui 1988) were deemed unsuitable because their items only addressed an adult population. In this particular research, since the aim was to know if parents and teachers valued individualism in their child or students, they had to complete a scale adapted to the age of those under examination. Additionally, previous scales, for the most part, also included some core components of collectivism. It is now well established that individualism 
and collectivism are not totally antithetical, but are defined in part by dimensions of their own (e.g., Gelfand et al. 1996; Tafarodi and Walters 1999). So an appropriate tool had to be constructed expressing items suited to the age of the students concerned: fourth, sixth and tenth graders, and related to the four individualistic components cited earlier. Some of these items have been inspired by existing instruments (e.g., the INDCOL Scale, Hui 1988).

Three different versions of the scale were developed (i.e., one for each school level: Fourth, sixth and tenth grade versions; see Appendix for example). The minor changes between these versions consisted of vocabulary adaptations. Each version is made up of 16 items (4 items by component, randomly distributed in the scale). These statements are presented in an affirmative form, using the "I" pronoun, each accompanied by a 6-point Likert scale ranging from 1 "totally disagree" to 6 "totally agree". Half of the items expressed the idea of high individualism (e.g., "I like very much the idea that I'm a unique person": Social differentiation component). The other half measured one's lack of individualistic tendencies (e.g., "I usually respect my friends' decisions, even if they disadvantage me": Self-realization component). ${ }^{1}$

\subsection{Procedure}

Parents and teachers, adopting the role of 'social evaluators', completed versions of the Individualism Scale adapted to the school level of their child or their students (for example, the fourth graders' teachers received the "fourth grade" version of the individualism scale, etc.).

Half of them were asked to complete the scale with a "normative instruction". So for each item, these parents and teachers had to choose the answer they would most like their child, or students, to give. In other words, they had to indicate how they expected their child, or their students, would complete the scale that would ultimately make a good impression.

The other participants were asked to complete the scale with a "counter-normative instruction". These parents and teachers had to choose each answer they would least

\footnotetext{
1 An internal validity analysis was made on the three versions of the Individualism Scale, among 87 fourth graders ( 42 boys and 45 girls; Mean Age $=10)$, 103 sixth graders ( 50 boys and 53 girls; Mean Age $=11.5$ ), and 110 tenth graders (43 boys and 67 girls; Mean Age = 15.5). Cronbach's alphas were $\alpha=.48$ for the "fourth graders' version", $\alpha=.55$ for the "sixth graders' version", and $\alpha=.63$ for the "tenth graders' version". Although these values are not very high according to conventional standards, they are very similar to those already obtained in the literature (e.g., Chan 1994: $\alpha=.51$; Hui 1988: $\alpha \mathrm{s}=.41$ to .68; Jetten et al. 2002: $\alpha=.66$; Robert and Wasti 2002: $\alpha=.67$; Somat, A. et al. 1994, unpublished manuscript: $\alpha=.42$ ), and they add to the frequently discussed problem of reliability for measures of individualism. The very richness of this construct makes its assessment so highly problematic (see Earley and Gibson 1998; Kashima et al. 1995; Robert et al. 2006). According to Cronbach (1990) attempts to measure broad concepts often result in low alpha coefficients of reliability. So these rather low values are primarily explained by the fact that the items exploit individualism, a complex and broad concept, through very different aspects of life, (e.g. school, family, and so forth), and different target-groups like friends, parents, and teachers (Chan 1994). Indeed, Hui (1988) has shown that the degree of individualism can vary noticeably as a function of target-groups and situations. Although this diversity results in a relatively low internal consistency, it ensures a better construct validity.
} 
like their child, or their students, to give. In other words, they had to indicate how they expected their child, or their students, would fill in the scale that would ultimately make a bad impression.

These two kinds of instructions were used to know if individualism is valued, or not, by these evaluators. Indeed, if the score given the normative instruction is significantly higher than the score given the counter-normative instruction, this would mean that individualism is judged desirable, since it gives a good image, or impression, of somebody. If it is the reverse, it would mean that individualism is judged undesirable, since its gives a bad image of somebody.

\section{Results}

The results are presented in five parts. The first section describes the results for the global score of individualism, followed by the results for the four sub-scores corresponding to each individualistic component. Each score was analysed by a three-way analysis of variance (ANOVA) with evaluators (parents versus teachers), instruction (normative versus counter-normative) and school level (fourth grade versus sixth grade versus tenth grade) as the independent variables. Since this was an exploratory study, the comparisons between the groups were systematically done with Tukey HSD posthoc tests.

\subsection{Global score of individualism}

No main effect was found for the instruction, $F(1,323)=.12$, ns. All evaluators and all school levels taken together, there was no difference between the normative instruction $(M=59.59, S D=11.04)$ and the counter-normative instruction $(M=58.93$, $S D=12.55)$.

However, an interaction effect between instruction and evaluators appeared, $F(1,323)=69.68, p<.0001, \eta^{2}=.18$. A Tukey HSD post-hoc test indicated at $p<.05$ that with all school levels taken together, parents valued the expression of individualism in their children $(M=63.48, S D=11.38$ with the normative instruction, and $M=54.86, S D=11.62$ with the counter-normative instruction). It was the exact opposite for the teachers: They did not value individualism for their students ( $M=64.36, S D=11.72$ with the counter-normative instruction, and $M=55.33$, $S D=8.93$ with the normative instruction).

The ANOVA revealed a three-way instruction $\times$ evaluators $\times$ school level interaction, $F(2,323)=8.15, p<.0001, \eta^{2}=.05$ (see Table 1 ). In order to better understand this interaction, the interaction effects between the instruction and the school level were analysed for each type of evaluator. For the parents, the two-way interaction was significant, $F(2,177)=34.10, p<.0001, \eta^{2}=.28$. The post-hoc contrasts indicated that the parents of sixth graders were the only ones who did not value individualism in their children, while the other parents judged it desirable. For the teachers, the interaction was not significant, $F(2,146)=2.42$, ns. 
Table 1 Means (and standard deviations) for individualism, as a function of evaluators, instruction and school level of students

\begin{tabular}{|c|c|c|c|c|c|}
\hline & & \multicolumn{4}{|l|}{ Evaluators } \\
\hline & & Parents & & & achers \\
\hline & \multirow[b]{2}{*}{$\begin{array}{l}\text { School level of } \\
\text { students }\end{array}$} & \multicolumn{4}{|c|}{ Instruction } \\
\hline & & $\begin{array}{l}\text { Normative } \\
\text { instruction }\end{array}$ & $\begin{array}{l}\text { Counter-normative } \\
\text { instruction }\end{array}$ & $\begin{array}{l}\text { Normative } \\
\text { instruction }\end{array}$ & $\begin{array}{l}\text { Counter-normative } \\
\text { instruction }\end{array}$ \\
\hline \multirow[t]{4}{*}{ Individualism } & Fourth grade & $69.74^{\mathrm{a}}(7.09)$ & $53.55^{\mathrm{b}}(10.20)$ & $60.79^{c}(7.03)$ & $68.91^{\mathrm{a}}(14.05)$ \\
\hline & Sixth grade & $52.13^{\mathrm{a}}(9.51)$ & $60.43^{\mathrm{b}}(10.60)$ & $51.74^{\mathrm{a}}(9.50)$ & $65.61^{\mathrm{b}}(8.53)$ \\
\hline & Tenth grade & $68.37^{\mathrm{a}}(7.72)$ & $50.77^{\mathrm{b}}(12.11)$ & $53.32^{\mathrm{bc}}(7.63)$ & $59.00^{\mathrm{c}}(10.26)$ \\
\hline & Global mean & $63.48^{\mathrm{a}}(11.38)$ & $54.86^{\mathrm{b}}(11.62)$ & $55.33^{\mathrm{b}}(8.93)$ & $64.36^{\mathrm{a}}(11.72)$ \\
\hline
\end{tabular}

Note. Means in the same row that do not share letters differ at a significance level of at least $p<.05$

\subsection{Sub-score of self-realization}

There was no main effect for instruction, $F(1,323)=.29$, ns $(M=14.96, S D=3.99$, with the normative instruction, and $M=14.43, S D=5.24$, with the counter-normative instruction).

A two-way interaction effect between instruction and evaluators was found, $F(1,323)=31.74, p<.0001, \eta^{2}=.09$. A post-hoc test of Tukey HSD indicated that, with all school levels taken together, parents valued self-realization in their children $(M=16.38, S D=3.85$ with the normative instruction, and $M=13.46$, $S D=5.24$ with the counter-normative instruction), while teachers did not value it in their students $(M=15.72, S D=4.98$ with the counter-normative instruction, and $M=13.40, S D=3.54$ with the normative instruction).

A three-way instruction $\times$ evaluators $\times$ school level interaction was also found, $F(2,323)=7.72, p=.001, \eta^{2}=.05$ (see Table 2$)$. The instruction $\times$ school level interaction was not significant for the teachers, $F(2,146)=1.82$, ns, but it was reliable for the parents, $F(2,177)=17.96, p<.0001, \eta^{2}=.17$. Parents valued this characteristic for their fourth grade and tenth grade children. Sixth graders' parents had the opposite results, but the difference between the two instructions was only marginally significant.

\subsection{Sub-score of autonomy}

At first sight, autonomy seemed to be valued $(M=16.284, S D=4.15$ with the normative instruction, and $M=14.92, S D=4.49$ with the counter-normative instruction), $F(1,323)=7.06, p=.008, \eta^{2}=.02$.

However, this main effect was qualified by a significant interaction between instruction and evaluators, $F(1,323)=29.46, p<.0001, \eta^{2}=.08$. A Tukey HSD test revealed that autonomy is only valued by parents $(M=17.42, S D=4.26$ with the normative instruction, and $M=14.02, S D=4.64$ with the counter-normative 
Table 2 Means (and standard deviations) for each individualistic component, as a function of evaluators, instruction and school level of students

\begin{tabular}{|c|c|c|c|c|c|}
\hline \multirow[b]{4}{*}{$\begin{array}{l}\text { Individualistic } \\
\text { component }\end{array}$} & \multirow[b]{4}{*}{$\begin{array}{l}\text { School level } \\
\text { of students }\end{array}$} & \multicolumn{4}{|l|}{ Evaluators } \\
\hline & & \multicolumn{2}{|c|}{ Parents } & \multicolumn{2}{|c|}{ Teachers } \\
\hline & & \multicolumn{4}{|c|}{ Instruction } \\
\hline & & $\begin{array}{l}\text { Normative } \\
\text { instruction }\end{array}$ & $\begin{array}{l}\text { Counter-normative } \\
\text { instruction }\end{array}$ & $\begin{array}{l}\text { Normative } \\
\text { instruction }\end{array}$ & $\begin{array}{l}\text { Counter-normative } \\
\text { instruction }\end{array}$ \\
\hline \multirow[t]{4}{*}{ Self-realization } & Fourth grade & $18.55^{\mathrm{a}}(3.22)$ & $11.94^{\mathrm{b}}(4.95)$ & $13.57^{\mathrm{bc}}(2.57)$ & $16.91^{\mathrm{ac}}(5.04)$ \\
\hline & Sixth grade & $13.97^{\mathrm{a}}(3.51)$ & $16.23^{\mathrm{a}}(4.69)$ & $12.96^{\mathrm{a}}(4.48)$ & $16.22^{\mathrm{a}}(4.91)$ \\
\hline & Tenth grade & $16.57^{\mathrm{a}}(3.43)$ & $12.29^{\mathrm{b}}(5.11)$ & $13.64^{\mathrm{ab}}(3.46)$ & $14.17^{\mathrm{ab}}(4.80)$ \\
\hline & Global mean & $16.38^{a}$ & $13.46^{\mathrm{b}}(5.24)$ & $13.40^{\mathrm{b}}(3.54)$ & $15.72^{\mathrm{a}}(4.98)$ \\
\hline \multirow[t]{4}{*}{ Autonomy } & Fourth grade & $18.87^{\mathrm{a}}(3.78)$ & $14.06^{\mathrm{b}}(3.60)$ & $16.39^{\mathrm{ab}}(3.40)$ & $17.41^{\mathrm{ab}}(4.14)$ \\
\hline & Sixth grade & $13.93^{\mathrm{a}}(3.94)$ & $16.63^{\mathrm{a}}(4.08)$ & $14.37^{\mathrm{a}}(3.94)$ & $17.04^{\mathrm{a}}(3.18)$ \\
\hline & Tenth grade & $19.40^{\mathrm{a}}(2.69)$ & $11.45^{\mathrm{b}}(4.75)$ & $14.29^{\mathrm{b}}(3.30)$ & $14.04^{\mathrm{b}}(3.93)$ \\
\hline & Global mean & $17.42^{a}(4.26)$ & $14.02^{b}(4.64)$ & $15.02^{\mathrm{b}}(3.65)$ & $16.12^{\mathrm{ab}}(4.02)$ \\
\hline \multirow[t]{4}{*}{ Emotional independence } & Fourth grade & $15.00^{\mathrm{ab}}$ & $14.84^{\mathrm{ab}}(4.09)$ & $12.89^{\mathrm{a}}(3.11)$ & $17.59^{\mathrm{b}}(4.46)$ \\
\hline & Sixth grade & $10.13^{\mathrm{a}}(4.16)$ & $15.40^{\mathrm{b}}(4.92)$ & $9.93^{\mathrm{a}}(2.62)$ & $17.78^{\mathrm{b}}(4.01)$ \\
\hline & Tenth grade & $13.07^{\mathrm{ac}}(3.61)$ & $15.74^{\mathrm{ad}}(4.83)$ & $10.07^{\mathrm{c}}(2.93)$ & $18.00^{\mathrm{d}}(4.05)$ \\
\hline & Global mean & $12.76^{\mathrm{a}}(4.33)$ & $15.33^{\mathrm{b}}(4.59)$ & $10.98^{\mathrm{c}}(3.17)$ & $17.80^{\mathrm{d}}(4.11)$ \\
\hline \multirow[t]{4}{*}{ Social differentiation } & Fourth grade & $17.32^{\mathrm{a}}$ & $12.71^{\mathrm{b}}(5.37)$ & $17.93^{\mathrm{a}}(3.22)$ & $17.00^{\mathrm{a}}(6.10)$ \\
\hline & Sixth grade & $14.10^{\mathrm{a}}(3.58)$ & $12.17^{\mathrm{a}}(4.44)$ & $14.48^{\mathrm{a}}(3.99)$ & $14.57^{\mathrm{a}}(4.36)$ \\
\hline & Tenth grade & $19.33^{\mathrm{a}}(3.80)$ & $11.29^{\mathrm{b}}(4.40)$ & $15.32^{\mathrm{c}}(4.46)$ & $12.79^{\mathrm{bc}}(4.43)$ \\
\hline & Global mean & $16.92^{\mathrm{a}}(4.50)$ & $12.05^{\mathrm{b}}(4.75)$ & $15.93^{\mathrm{ac}}(4.15)$ & $14.72^{\mathrm{c}}(5.22)$ \\
\hline
\end{tabular}

Note. Means in the same row that do not share letters differ at a significance level of at least $p<.05$

instruction). The difference between the two kinds of instructions was not significant for teachers $(M=16.12, S D=4.02$ with the normative instruction, and $M=15.02$, $S D=3.65$ with the counter-normative instruction).

A three-way instruction $\times$ evaluators $\times$ school level interaction was found, $F(2,323)=7.86, p<.0001, \eta^{2}=.04$ (see Table 2$)$. The instruction $\times$ school level interaction was not significant for teachers, $F(2,146)=2.03$, ns, but it was for parents, $F(2,177)=30.35, p<.0001, \eta^{2}=.26$. Parents valued autonomy for the fourth graders and tenth graders. The tendency was reversed for the sixth graders' parents, while not significant.

\subsection{Sub-score of emotional independence}

A main effect for instruction was highly reliable, $F(1,323)=117.27, p<.0001$, $\eta^{2}=.27$. Participants did not value emotional independence $(M=16.39, S D=4.55$ with the counter-normative instruction, and $M=11.91, S D=3.92$ with the normative instruction). 
A two-way interaction between instruction and evaluators was also found, $F(1,323)=23.69, p<.0001, \eta^{2}=.07$. The Tukey HSD test indicated that the prior main effect was stronger for teachers $(M=17.80, S D=4.11$ with the counternormative instruction, and $M=10.98, S D=3.17$ with the normative instruction) than for parents $(M=15.33, S D=4.59$ with the counter-normative instruction, and $M=12.76, S D=4.33$ with the normative instruction). It was also observed that the difference between the two instructions was significant for the two kinds of evaluators.

For this individualistic component, there was no three-way interaction (i.e. instruction $\times$ evaluators $\times$ school level $), F(2,323)=.90$, ns (see Table 2$)$.

\subsection{Sub-score of social differentiation}

Here again, there was a main effect for instruction, indicating that social differentiation is valued $(M=16.45, S D=4.35$ with the normative instruction, and $M=13.20$, $S D=5.12$ with the counter-normative instruction), $F(1,323)=37.93, p<.0001$, $\eta^{2}=.11$.

The ANOVA showed also a two-way interaction between instruction and evaluators, $F(1,323)=14.78, p<.0001, \eta^{2}=.04$. The Tukey HSD test indicated that the prior effect was only significant when the evaluators were the parents $(M=16.92$, $S D=4.50$ with the normative instruction, and $M=12.05, S D=4.75$ with the counter-normative instruction). Indeed, the difference between the two instructions was not significant for teachers $(M=15.93, S D=4.15$ with the normative instruction, and $M=14.72, S D=5.22$ with the counter-normative instruction).

No three-way interaction, instruction $\times$ evaluators $\times$ school level, was found for the sub-score of social differentiation, $F(2,323)=1.08$, ns (see Table 2$)$.

\section{Discussion}

The global aim of this study was to examine if the students' expression of individualism at different educational levels is valued by their parents and teachers in a Western society such as France.

The results showed firstly that the manifestation of individualism is valued differently depending on the evaluator. A major difference appeared between parents and teachers. With all school levels taken together, parents appreciated individualism in their children. This point is consistent with previous research which suggests that Euro-American families tend to endorse individualist characteristics as important for their children (Jose et al. 2000; Leyendecker et al. 2002; Suizzo 2004). On the other hand, teachers actually devalued the expression of individualism for their students. This result is contrary to the assumptions made by numerous researchers who think that individualism is present and valued in academic institutions (e.g., Ranjard 1997). Instead, it seems that individualistic students are not highly valued in the eyes of these evaluators.

The analyses of the sub-scores of the four individualistic dimensions allowed a refinement of this initial assessment. Self-realization represented the dimension for 
which the judgements of the two kinds of evaluators were the most different. Parents valued it for their children, except when evaluating sixth graders. Teachers rather undervalued the idea that their students give priority to their own personal interests and goals over the collective ones. If, for these two kinds of evaluators, generally it appears to be social convention to emphasize personal success particularly at school, it is possible to further speculate that teachers also see self-realization as a sign of selfishness in group situations (i.e., meaning "I'm only interested in myself, not in others", "me first, the others after", etc.).

With regards to the autonomy theme, parents wished their children to behave and make decisions on their own, except, again, the sixth graders. It is noticeable that the valuation of autonomy by the majority of parents supports some developmental studies (e.g., Bandura and Walters 1959; Feldman and Wood 1994) and cross-cultural research (e.g., Rose 1999; Stewart et al. 1999), which have shown that, in Western societies, parents encourage autonomy in their children. For the teachers, there is more uncertainty about the valuation of this component. Such a result can perhaps be explained by the fact that school is a place where autonomy is limited by ubiquitous social influence (i.e., through group activities, control and instruction) making it difficult for students to do freely what they want without taking others into account.

The exhibition of emotional independence was negatively judged by all the evaluators, even more by the teachers. Indeed, all of them devalued the idea that their children, or students, would show a certain detachment from others. Moreover, this dimension is the most criticized aspect of individualism in the literature, partly because of its comparison to narcissism and egoism (e.g., Lasch 1978), but undoubtedly because it is seen as a risk able to disrupt the smooth running of interpersonal relations (Lorenzi-Cioldi 1995), that are predominant in families as well as at school.

Finally, social differentiation appeared as a component valued by parents. This result supports previous ones (e.g., Nichols 2002), and it also corroborates Codol's hypothesis (1984) that the 'search of difference' is probably more valued in our societies than the 'search of similarity'. Likewise, Kim and Markus (1999) have shown experimentally that in Western cultures, people judge uniqueness as a desirable characteristic. For the teachers, however, there is more uncertainty (no difference between the two instructions). This is perhaps because striving to differentiate one-self too much from others in a classroom can be also seen as a sign of antisocial behaviour directed towards the rest of the group.

To sum up, teachers and parents do not have the same expectations for the way their students or their children must present themselves. That is to say that the valuation of individualism as a whole, and its components, are a function of the social context since they are judged differently depending on the evaluators.

This study gives food for thought that parents tend to emphasize values promoting the individualism of their child, through freedom, uniqueness, and so forth. It is noticeable here that the sixth graders' parents were the only ones to not value individualism in their children. It could be explained by these students' radical change of status as they move from being the oldest in primary education to the youngest in junior high school. Perhaps such an abrupt change leaves parents wishing for a stronger integration for their child. It is worth noting that Loose's study (2001), cited above, designed to examine the evolution with age of individualism, showed 
that sixth graders were significantly less individualistic than younger students of primary education and older ones. These results seem to indicate that individualism would be actually the subject of a social acquisition, especially in the familial institution.

Teachers tend to favour values that encourage more relatedness and taking others into consideration. Probably this can be partly explained by the fact that these evaluators, contrary to parents, on a day-to-day basis have little interaction with isolated individuals, but with a classroom-group, a kind of "miniature society" (Gaonac'h and Golder 1995). They certainly perceive their students as elements integrated in relationships and social networks (with their peers amongst others). It is then fair to say that individualism is more devalued at school, which is ultimately a group context. This is because it is probably interpreted more as deviance that could threaten the group's unity, even its productivity (McAuliffe et al. 2003).

From these results many socio-institutional conflicts are conceivable since parents and teachers do not value the same characteristics in children. We could also hypothesize, however, that evolution in these two different institutional contexts could allow children to find a balance between their psychological needs of individuation and connectedness, of differentiation and inclusion (Brewer and Pickett 1999). This balance appears to be the most beneficial for their overall adjustment (Greenfield et al. 2003). In other words, they could fulfil their fundamental needs to belong to social groups and, at the same time, defend their individual identity (Hornsey and Jetten 2004).

Although the findings in the present research add to a growing body of literature in the individualism area, a number of limitations merit consideration and must be mentioned.

Firstly, it is important to emphasise that this was a study of parents' and teachers' expectations and wishes and not of their actual practices. It is well known, however, that dissociation between attitudes and behaviours often exists. So it would now be interesting, and essential, to examine the social value of individualism through other methods of investigation, like for example real observation of interaction in families and schools.

Secondly, some variables that could be expected to influence the valuation of individualism by parents and teachers were not included in this research. For example, the gender of the students had not been taken into account. Several studies, however, have shown that in a general way boys are more individualist than girls (cf. Cross and Madson 1997; Loose 2001). So the question arises as to whether parents and teachers, as social evaluators, value individualism differently as a function of the students' gender. Therefore, further analyses looking at the possible effects of this kind of variable should be conducted.

Thirdly, we should examine further the sixth graders because these students' parents substantially differ in their responses from other parents. It would be worthwhile to find out more about these results.

Finally, it would be necessary, now, to study the value of individualism in other important evaluative institutions, like professional contexts (e.g., recruiters in organizations and their judgements of the manifestation of individualistic values and behaviours in job candidates). In such a situation, does appearing as an individualistic person make a good or a bad impression? Would these other evaluators have the same 
judgements as teachers or parents? Indeed, it would be valuable to identify more accurately the social contexts in which it is advantageous to present oneself as an individualist, and those in which it is a hindrance.

Despite these limitations, the current study does make a contribution to the literature by studying under-examined individualistic populations: French parents and teachers. It adds to a growing body of research that is beginning to take a closer look at the social value of individualism (e.g., Dubois and Beauvois 2005; Jetten et al. 2002). It also shows the necessity of examining individualism, not only as a whole, but through each of its main components, especially since some of the components appear more valued than others.

In summary, our findings show here the impact of several factors on the valuation of individualism by highlighting important differences between social evaluators, students' educational level and individualistic components.

Acknowledgements The author gratefully acknowledges Michaël Dambrun for his advice on an earlier version of this paper.

\section{Appendix}

\section{Individualism scale "Sixth Grade Version"}

Individualistic dimension Items numbers

$\begin{array}{ll}\text { Self-realization } & 3,9,11,14 \\ \text { Autonomy } & 2,6,7,12 \\ \text { Emotional independence } & 4,10,13,16 \\ \text { Social differentiation } & 1,5,8,15\end{array}$

1. When I buy new clothes, I try to choose them so I'm the only one wearing them at school
Totally disagree
12
355
6 Totally agree

2. When I have to make an important choice, I don't mind what the others tell me to do, I decide by myself
Totally disagree 1

3. At school, I prefer working alone rather than working with somebody worse than me
Totally disagree
23
45
56
Totally agree

4. When I have worries, I usually don't talk about them with my friends $\begin{array}{llllllll}\text { Totally disagree } & 1 & 2 & 3 & 4 & 5 & 6 & \text { Totally agree }\end{array}$

5. I like, very much, to wear the same clothes as the other students in my class $\begin{array}{llllllll}\text { Totally disagree } & 1 & 2 & 3 & 4 & 5 & 6 & \text { Totally agree }\end{array}$

6. I usually do exactly what I want, without wondering what the others think about it
Totally disagree
23
34
56 Totally agree

7. When I have a problem, I sort it out alone without being influenced by my friends' advice

$\begin{array}{llllllll}\text { Totally disagree } & 1 & 2 & 3 & 4 & 5 & 6 & \text { Totally agree }\end{array}$ 
8. I like the idea I am a unique person, who doesn't look like other people $\begin{array}{llllllll}\text { Totally disagree } & 1 & 2 & 3 & 4 & 5 & 6 & \text { Totally agree }\end{array}$

9. When my mates slow me down at school, I nevertheless stay with them, even if I could have better results alone

$\begin{array}{llllllll}\text { Totally disagree } & 1 & 2 & 3 & 4 & 5 & 6 & \text { Totally agree }\end{array}$

10. When one of my friends is insulted, I feel insulted myself

$\begin{array}{llllllll}\text { Totally disagree } & 1 & 2 & 3 & 4 & 5 & 6 & \text { Totally agree }\end{array}$

11. I usually try to live by thinking first about others before thinking about me

$\begin{array}{llllllll}\text { Totally disagree } & 1 & 2 & 3 & 4 & 5 & 6 & \text { Totally agree }\end{array}$

12. I always take into account the others' opinions when choosing new clothes

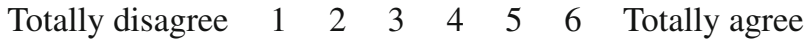

13. When I have a secret, I like to share it with my friends

$\begin{array}{llllllll}\text { Totally disagree } & 1 & 2 & 3 & 4 & 5 & 6 & \text { Totally agree }\end{array}$

14. At school, I am first and foremost concerned about my personal success

$\begin{array}{llllllll}\text { Totally disagree } & 1 & 2 & 3 & 4 & 5 & 6 & \text { Totally agree }\end{array}$

15. In general, I think that my personality doesn't look like anybody else's personality Totally disagree $\quad \begin{array}{lllllll}1 & 2 & 3 & 4 & 5 & 6 & \text { Totally agree }\end{array}$

16. During playtime, if I see a student crying, I generally try to speak with him/her in order to know what's going wrong

$\begin{array}{llllllll}\text { Totally disagree } & 1 & 2 & 3 & 4 & 5 & 6 & \text { Totally agree }\end{array}$

\section{References}

Bandura, A., \& Walters, R. H. (1959). Adolescent aggression. New York: Ronald Press.

Bellah, R. N., Madsen, R., Sullivan, W. M., Swidler, A., \& Tipton, S. M. (1985). Habits of the heart: Individualism and commitment in American life. Berkeley: University of California Press.

Bierbrauer, G., Meyer, H., \& Wolfradt, U. (1994). Measurement of normative and evaluative aspects in individualistic and collectivistic orientations: The cultural orientation scale (COS). In U. Kim, H. C. Triandis, C. Kagitçibasi, S. C. Choi, \& G. Yoon (Eds.), Individualism and collectivism: Theory, methods and applications (pp. 189-199). Thousand Oaks: Sage Publication.

Brewer, M. B., \& Pickett, C. L. (1999). Distinctiveness motives as a source of the social self. In T. Tyler, R. Kramer, \& O. John (Eds.), The psychology of the social self (pp. 71-87). Mahwah, NJ: Erlbaum.

Chan, D. K.-S. (1994). COLINDEX: A refinement of three collectivism measures. In U. Kim, H. C. Triandis, C. Kagitçibasi, S. C. Choi, \& G. Yoon (Eds.), Individualism and collectivism: Theory, methods and applications (pp. 200-212). Thousand Oaks: Sage Publication.

Codol, J. P. (1984). Social differentiation and non- differentiation. In H. Tajfel (Ed.), The social dimension. Cambridge: Cambridge University Press.

Cronbach, L. J. (1990). Essentials of psychological testing (5th ed.). New York: Harper/Collins.

Cross, S. E., \& Madson, L. (1997). Models of the self: Self-construals and gender. Psychological Bulletin, $122,5-37$.

Damon, W. (1995). Greater expectations: Overcoming the culture of indulgence in America's homes and schools. New York: Free Press.

Dubois, N., \& Beauvois, J.-L. (1999). Normes libérales de jugement et individualisme/collectivisme. Communication presented at the Table Ronde "Cognitions et conduites sociale", Nice, September 1999.

Dubois, N., \& Beauvois, J.-L. (2005). Normativeness and individualism. European Journal of Social Psychology, 35, 123-146.

Earley, P. C., \& Gibson, C. B. (1998). Taking stock in our progress on individualism-collectivism: 100 years of solidarity and community. Journal of Management, 24, 265-304.

Estrin, E. T., \& Nelson-Barber, S. (1995). Issues in cross-cultural assessment: American Indian and Alaska Native students. Knowledge Brief. San Francisco: Far West Laboratory. 
Feldman, S. S., \& Wood, D. N. (1994). Parents' expectations for preadolescent boys' behavioural autonomy: A longitudinal study of correlates and outcomes. Journal of Research on Adolescence, 4, 45-70.

Fowers, B. J., Applegate, B., Tredinnick, M., \& Slusher, J. (1995). His and her individualisms? Sex bias and individualism in psychologist's responses to case vignettes. The Journal of Social Psychology, 130, 159-174.

Gaonac'h, D., \& Golder, C. (1995). Profession enseignant. Paris: Hachette.

Gecas, V. (1976). The socialization and child care roles. In F. I. Nye (Ed.), Role structure and analysis of the family. Beverly Hills: Sage.

Gelfand, M. J., Triandis, H. C., \& Chan, D. K.-S. (1996). Individualism versus collectivism or versus authoritarianism ? European Journal of Social Psychology, 26, 397-410.

Greenfield, P. M., Keller, H., Fuligni, A., \& Maynard, A. (2003). Cultural pathways through universal development. Annual Review of Psychology, 54, 461-490.

Harkness, S., Super, C. M., \& Keefer, C. H. (1992). Learning to be an American parent: How cultural models gain directive force. In R. G. D'Andrade \& C. Strauss (Eds.), Human motivation and cultural models (pp. 163-178). New York: Cambridge University Press.

Harwood, R. L. (1992). The influence of culturally derived values on Anglo and Puerto Rican mothers' perception of attachment behavior. Child Development, 63, 822-839.

Harwood, R. L., Miller, J. G., \& Lucca Irizarry, N. L. (1995). Culture and attachment: Perceptions of the child in context. New York: Guilford Press.

Harwood, R. L., Schoelmerich, A., Ventura-Cook, E., Schulze, P. A., \& Wilson, S. P. (1996). Culture and class influences on Anglo and Puerto Rican mothers' beliefs regarding long term socialization goals and child behavior. Child Development, 67, 2446-2461.

Hofstede, G. (1980). Culture's consequences: International differences in work-related values. Beverly Hills/London: Sage.

Hornsey, M. J., \& Jetten, J. (2004). The individual within the group: Balancing the need to belong with the need to be different. Personality and Social Psychology Review, 8, 248-264.

Hui, C. H. (1988). Measurement of individualism-collectivism. Journal of Research in Personality, 22, $17-36$.

Hui, C. H., \& Triandis, H. C. (1986). Individualism-collectivism: A study of cross-cultural researchers. Journal of Cross-Cultural Psychology, 17, 225-248.

Jetten, J., Postmes, T., \& McAuliffe, B. J. (2002). We're all individuals: Group norms of individualism and collectivism, levels of identification, and identity threat. European Journal of Social Psychology, 32, 189-207.

Jose, P. E., Huntsinger, C. S., Huntsinger, P. R., \& Liaw, F.-R. (2000). Parental values and practices relevant to young children's social development in Taiwan and the United States. Journal of Cross-Cultural Psychology, 31, 677-702.

Kashima, Y., Yamaguchi, S., Kim, U., Choi, S. C., Gelfand, M., \& Yuki, M. (1995). Culture, gender, and self: A perspective from individualism-collectivism research. Journal of Personality and Social Psychology, 69, 925-937.

Kim, H., \& Markus, H. R. (1999). Deviance or uniqueness, harmony or conformity: A cultural analysis. Journal of Personality and Social Psychology, 77, 785-800.

Lasch, C. (1978). The culture of narcissism: American life in an age of diminishing expectations. New York: Norton.

Leyendecker, B., Harwood, R. L., Lamb, M. E., \& Schölmerich, A. (2002). Mothers' socialisation goals and evaluations of desirable and undesirable everyday situations in two diverse cultural groups. International Journal of Behavioral Development, 26, 248-258.

Loose, F. (2000). L'individualisme, une norme sociale? Une approche expérimentale. Unpublished doctoral thesis, University of Clermont-Ferrand, France.

Loose, F. (2001). L'acquisition sociale de l'individualisme en fonction du niveau scolaire et du genre. Revue Internationale de Psychologie Sociale, 14, 55-70.

Lorenzi-Cioldi, F. (1995). Cognitions individuelles, culturelles, et sexuelles. Psychologie Française, 40, 331-337.

Markus, H. R., \& Kitayama, S. (1991). Culture and the self: Implications for cognition, emotion and motivation. Psychological Review, 98, 224-253.

McAuliffe, B. J., Jetten, J., Hornsey, M. J., \& Hogg, M. A. (2003). Individualist and collectivist norms: When it's ok to go your own way. European Journal of Social Psychology, 33, 57-70.

Mendras, H. (1997). L'Europe des Européens. Paris: Gallimard. 
Nichols, S. (2002). Parents' construction of their children as gendered, literate subjects: A critical discourse analysis. Journal of Early Childhood Literacy, 2, 123-144.

Ranjard, P. (1997). Les enjeux de l'éducation. Paris: L'Harmattan.

Realo, A., Koido, K., Ceulemans, E., \& Allik, J. (2002). Three components of individualism. European Journal of Personality, 16, 163-184.

Riesman, D., Glazer, N., \& Denney, R. (1961). The lonely crowd: A study of the changing American character. New Haven: Yale University Press.

Robert, C., Lee, W. C., \& Chan, K.-Y. (2006). An empirical analysis of measurement equivalence with the INDCOL measure of individualism and collectivism: Implications for valid cross-cultural inference. Personnel Psychology, 59, 65-99.

Robert, C., \& Wasti, S. A. (2002). Organizational individualism and collectivism: theoretical development and an empirical test of a measure. Journal of Management, 28, 544-566.

Rose, G. M. (1999). Consumer socialization, parental style, and developmental timetables in the United States and Japan. Journal of Marketing, 63, 105-119.

Sampson, E. E. (1977). Psychology and the American ideal. Journal of Personality and Social Psychology, $35,767-782$.

Sampson, E. E. (1988). The debate on individualism: Indigenous psychologies of the individual and their role in personal and societal functioning. American Psychologist, 43, 15-22.

Schwartz, S. H. (1994). Beyond individualism/Collectivism: New cultural dimensions of values. In U. Kim, H. C. Triandis, C. Kagitçibasi, S. C. Choi, \& G. Yoon (Eds.), Individualism and collectivism: Theory, methods and applications (pp. 85-120). Thousand Oaks: Sage Publication.

Stewart, S. M., Bond, M. H., Deeds, O., \& Chung, S. F. (1999). Intergenerational patterns of values and autonomy expectations in cultures of relatedness and separateness. Journal of Cross- Cultural Psychology, 30, 575-593.

Suizzo, M.-A. (2004). French and American mothers' childrearing beliefs: Stimulating, responding and long-term goals. Journal of Cross-Cultural Psychology, 35, 606-626.

Tafarodi, R. W., \& Walters, P. (1999). Individualism-collectivism, life events, and self-esteem: A test of two trade-offs. European Journal of Social Psychology, 29, 797-814.

Triandis, H. C. (1995). Individualism and Collectivism. Westview Press.

Triandis, H. C., McCusker, C., \& Hui, C. H. (1990). Multimethod probes of individualism and collectivism. Jounal of Personality and Social Psychology, 59, 1006-1020.

Trumbull, E., Rothstein-Fisch, C., \& Greenfield, P. M. (2000). Bridging cultures in our schools: New approaches that work. Knowledge Brief. San Francisco: WestEd.

Vignoles, V. L., Chryssochoou, X., \& Breakwell, G. M. (2000). The distinctiveness principle: Identity, meaning and the bounds of cultural relativity. Personality and Social Psychology Review, 4, 337-354.

Waterman, A. S. (1981). Individualism and interdependence. American Psychologist, 36, 762-773.

Yamaguchi, S. (1994). Collectivism among the Japanese: A perspective from the self. In U. Kim, H. C. Triandis, C. Kagitçibasi, S. C. Choi, \& G. Yoon (Eds.), Individualism and collectivism: Theory, methods and applications (pp. 175-188). Thousand Oaks: Sage Publication.

Yang, K. S. (1988). Will societal modernization eventually eliminate cross-cultural psychological differences? In M. H. Bond (Ed.), The cross-cultural challenge to social psychology (pp. 67-85). Newbury Park: Sage.

\section{Author Biography}

Florence Loose received her Ph.D in Social Psychology in 2000 (at the University Blaise Pascal, ClermontFerrand, France). She is an Assistant Professor, and an associate member of the "Laboratoire de Psychologie Sociale et Cognitive" (LAPSCO, UMR CNRS 6024, University of Clermont-Ferrand, France). Her research focuses on individualism in family, school, and organizational contexts. Her other interest is concerned with academic performances and school disengagement in French students and ethnic minority students. 